\title{
Linking sedimentary phosphate U-Pb ages to syn-sedimentary processes
}

GARY J. O'SULLIVAN ${ }^{1}$, J STEPHEN DALY ${ }^{1}$, JOHN

MURRAY ${ }^{2}$, AODHÁN Ó'GOGÁIN ${ }^{2}$, DAVID M $\mathrm{CHEW}^{3}$, ESZTER BADENSZKI ${ }^{1}$, BRENDAN HOARE ${ }^{3}$, PAUL GUYETT $^{3}$ AND FOTEINI DRAKOU ${ }^{3}$

${ }^{1}$ University College Dublin

${ }^{2}$ National University of Ireland, Galway

${ }^{3}$ Trinity College Dublin

Presenting Author: gary.osullivan@ucd.ie

Simultaneous measurement of U-Pb isotopic and trace element geochemical data in authigenic apatite by LA-Q-ICPMS can greatly improve the confidence with which the age data from sedimentary phosphate can be interpreted. By demonstrating consistency between phosphate chemistry and phosphate petrography, we show that it is possible to link $\mathrm{U}-\mathrm{Pb}$ ages to early diagenetic and sedimentary reworking processes, and to detect and exclude areas affected by later alteration.

We have undertaken this study on authigenic apatite from phosphate nodules, phosphorites and phosphate cements from the Shannon Basin, a Carboniferous intracontinental sedimentary basin in western Ireland. Our data allow us to construct a chronostratigraphy for these phosphatic sediments and to clarify aspects of the timing of the sedimentary infill. We detect a hitherto ill-defined major disconformity present at a consistent stratigraphic level across the northern margin of the basin. This disconformity corresponds to the boundary of the Serpukhovian and Bashkirian stages, and thus to the mid-Carboniferous (Mississippian-Pennsylvanian) boundary. Importantly, our findings are compatible with, and complement, the existing stratigraphy based on conodont and ammonoid biozonation. This includes conodont analysis we have carried out in the same sampled sections.

Precision on the ages obtained for the analysed phosphates can be very high, with $2 \sigma$ uncertainties as low as $0.65 \%$ and the MSWD values of U-Pb discordia are consistently close to 1 . However, we emphasise that integration of rare earth element chemistry within the same aliquots used to obtain $\mathrm{U}-\mathrm{Pb}$ ages is absolutely essential to demonstrate the fidelity of phosphate ages to early sedimentary processes, rather than later alteration or deep diagenesis. Ratios of $\mathrm{Eu} / \mathrm{Eu}^{*}$; $\mathrm{Ce} / \mathrm{Ce}$; various $\mathrm{REEs}$ and $\mathrm{Th} / \mathrm{U}$ etc. have proven useful for this purpose, including plots developed, e.g., by Reynard et al. (1999) to detect alteration in sedimentary phosphates.

Reference

Reynard, B., Lécuyer, C. and Grandjean, P., 1999. Crystalchemical controls on rare-earth element concentrations in fossil biogenic apatites and implications for paleoenvironmental reconstructions. Chemical Geology, 155(3-4), pp.233-241. 